A 80

VILNIAUS GEDIMINO

\title{
Finite element analysis of osteoporotic
}

\section{lumbar vertebrae L1 under dynamic loading}

Oleg Ardatov

Faculty of Mechanics,

Vilnius Gediminas Technical University
Vidmantas Alekna

Faculty of Medicine
Algirdas Maknickas

Institute of Mechanical Science,

Vilnius Gediminas Technical University
Marija Tamulaitienė

Faculty of Medicine,

Vilnius University
Rimantas Kačianauskas

Institute of Mechanical Science,

Vilnius Gediminas Technical University

\section{NTRODUCTION}

Osteoporosis impacts the micro-architectural structure of bone tissue and increases fracture risk [1]. Vertebral fractures in particular result in a high mortality rate [2]. Although osteoporoSis affects the entire skeleton, many fragility fractures occur in
the lumbar spine [3]. The present study is aimed to investigate the influence of osteoporosis on the mechanical behavior of the the influence

\section{MODELLING}

Problem formulation

The three-dimensional static FEM analysis was performed in order to define the mechanical behavior of human lumbar vertebrae L1 model under the compression load. Theory of elasticity was applied.

he Vone tissue is modelled as elastoplastic continuum, so the Von Mises-Hencky criterion is chosen to predict the failure cal properties of the bone, which seem to behave as a ductile $\mathrm{ma-}$ terial [4], [5]. Also, the structure of model is continuous, so the Von Mises stress criterion is applied on research of stresses, which occur on cortical shell of the model.

Structure of the model

The inhomogeneous lumbar vertebrae body consists of two er cortical shell fulfilled by inn bone tissue. The initial anatomical geometry of the developed vertebrae body model is illustrated in Fig. 3 .

\section{Material properties}

Both cancellous trabecular bone and surrounding compact bone (cortical shell) are modelled as elastoplastic transversally orthotropic continuum. The stress-strain curve for cortical bone in main axial direction is presented in Fig. 1. Intervertebral disks
were assumed isotropic and perfectly elastic. Mechanical properties of model members are presented in Table

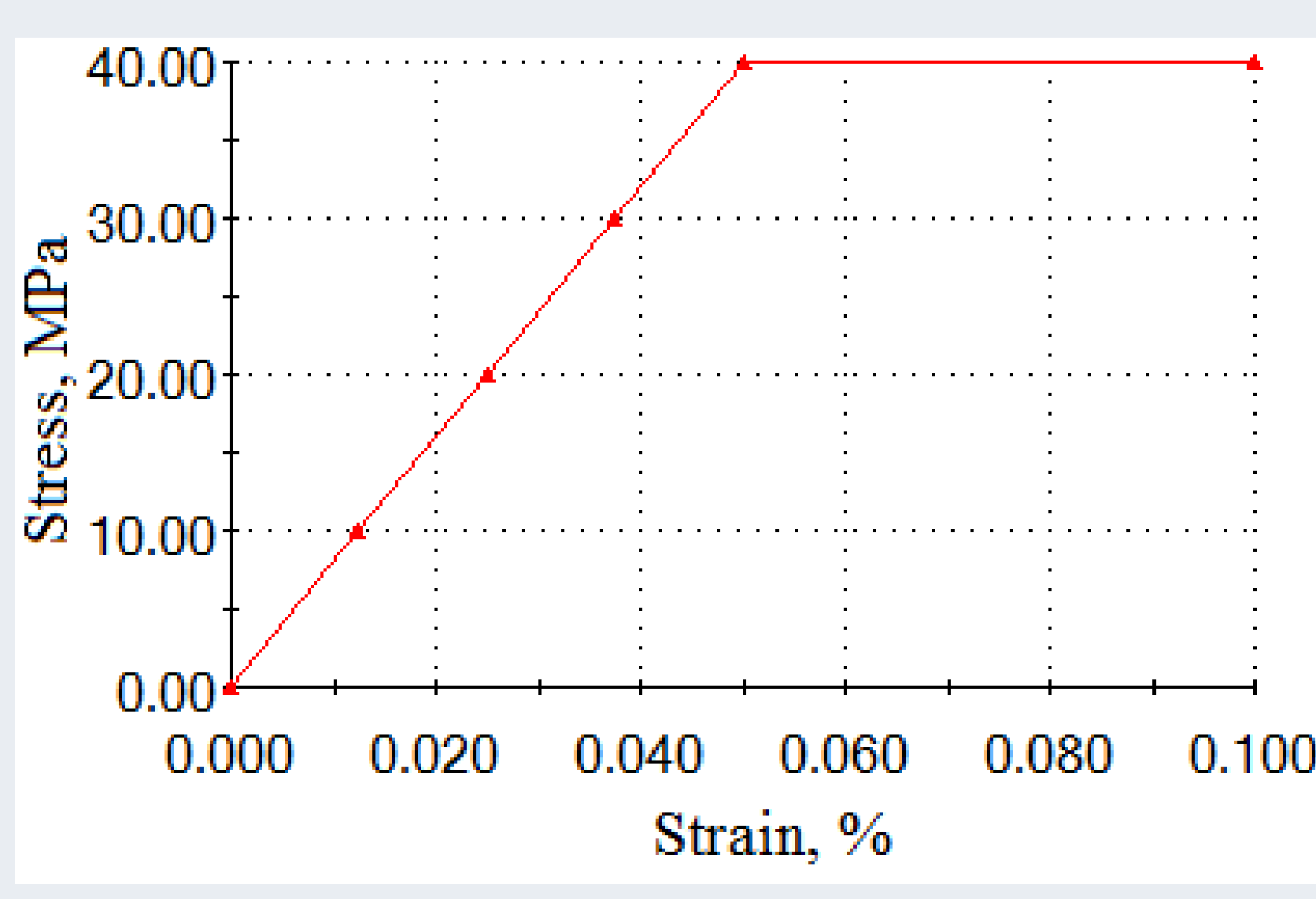

Fig. 1: Stress-strain curve for cortical bone

Osteoporotic influence for the vertebrae is characterised by decreasing modulus of elasticity of cancellous bone. Modulus of cancellous bone is determined according to power-law equations,
which reflect the impact of apparent density. The selection of this which reflect the impact of apparent density. The selection of this
equation is based on alignment of our research and data pubequation is based on align
lished by Helgason et. al.[6]

$\mathrm{E}_{\text {cancellous }}=4.730 \rho^{1.56}$

where $\rho$ is apparent density. In current research it is in range between 0.10 and $0.30 \mathrm{~g} / \mathrm{cm}^{3}$.

Table 1. Elasticity constants and density parameters
\begin{tabular}{|c|c|c|c|c|c|}
\hline Component & $\mathrm{E}_{\mathrm{z}}, \mathrm{MPa}$ & $\mathrm{E}_{\mathrm{x}}=\mathrm{E}_{\mathrm{y}}, \mathrm{MPa}$ & $v_{\mathrm{z}}$ & $v_{\mathrm{x}}=v_{\mathrm{y}}$ & $\rho, \mathrm{g} / \mathrm{cm}^{3}$ \\
\hline Cortical shell & 8000 & 2500 & 0.30 & 0.200 & - \\
\hline Trabec. bone & $130-720$ & $42-240$ & 0.30 & 0.200 & $0.10-0.30$ \\
\hline Inter. disk & 10 & 10 & 0.495 & 0.495 & - \\
\hline
\end{tabular}

Loads and boundary conditions

The bone is subjected by the physiological loads, which occur through daily activities. Generally, it presents the axially acting pressure load (Fig. 2). The model was meshed with tetrahedral finite elements due to its curvature. The number of finite 16597, as for the most important part of the model. In order accelerate calculations, the number of finite elements of cancellous bone was 12915, the number of nodes -18313 . The the number of nodes -5677 , for it's not the primary part of the model.

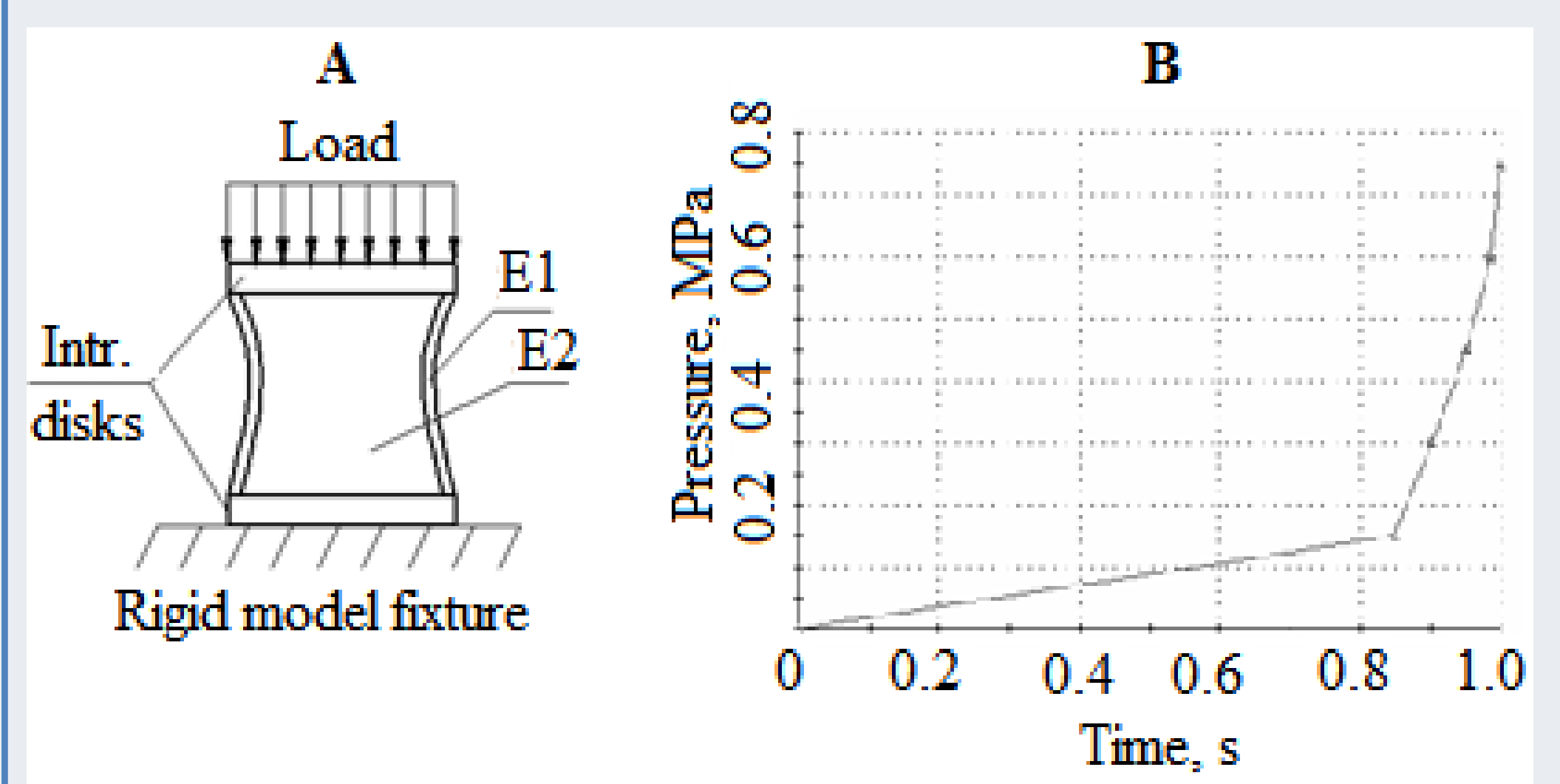

Fig. 2. A: Schematization of load due to compression test;

E2 - cancellous bone; B: time variation of load

The Brigade/Plus software was used.
MODEL STRUCTURE

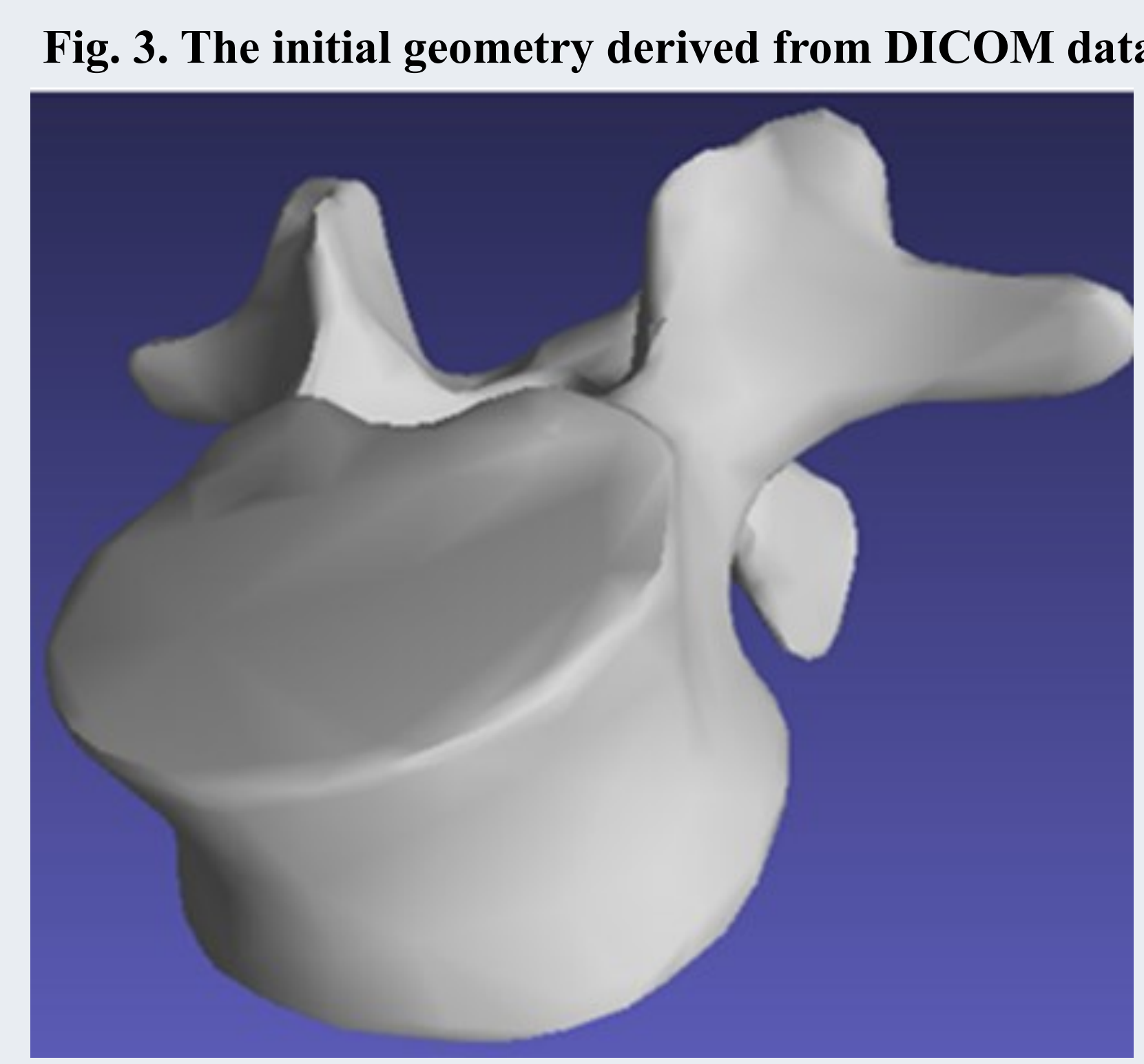

Fig. 4. Components of the numerical model
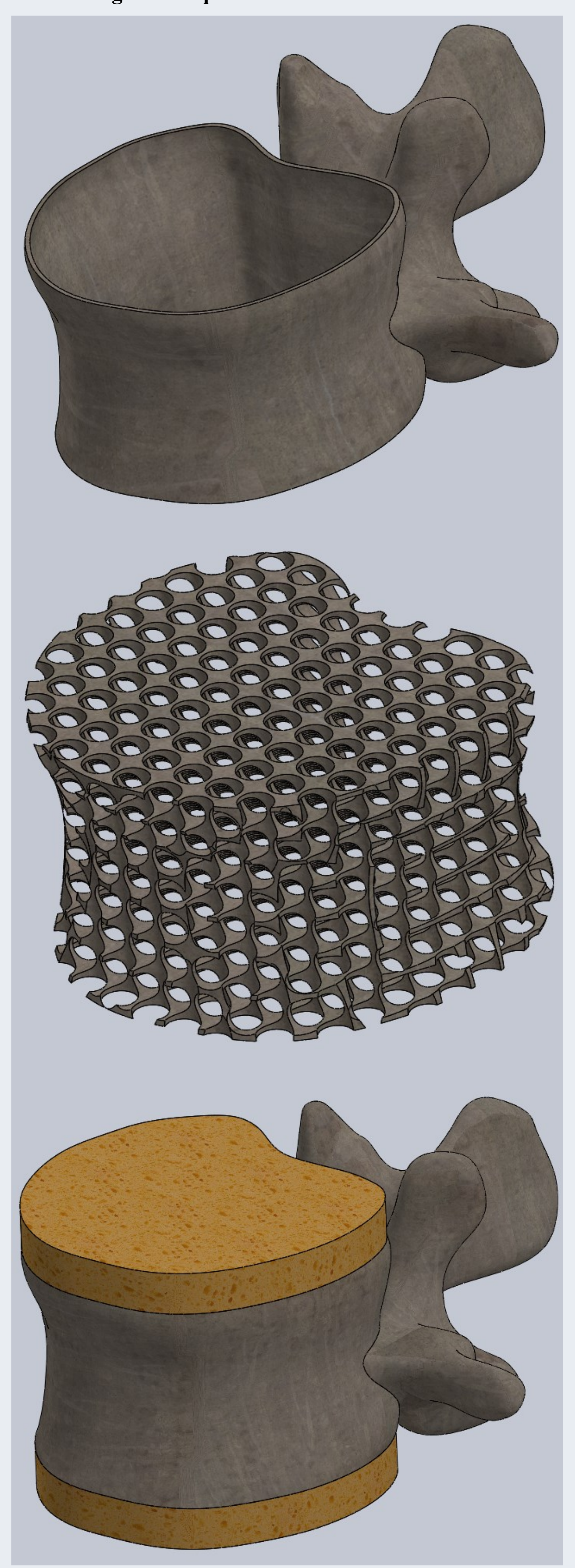

NUMERICAL RESULTS

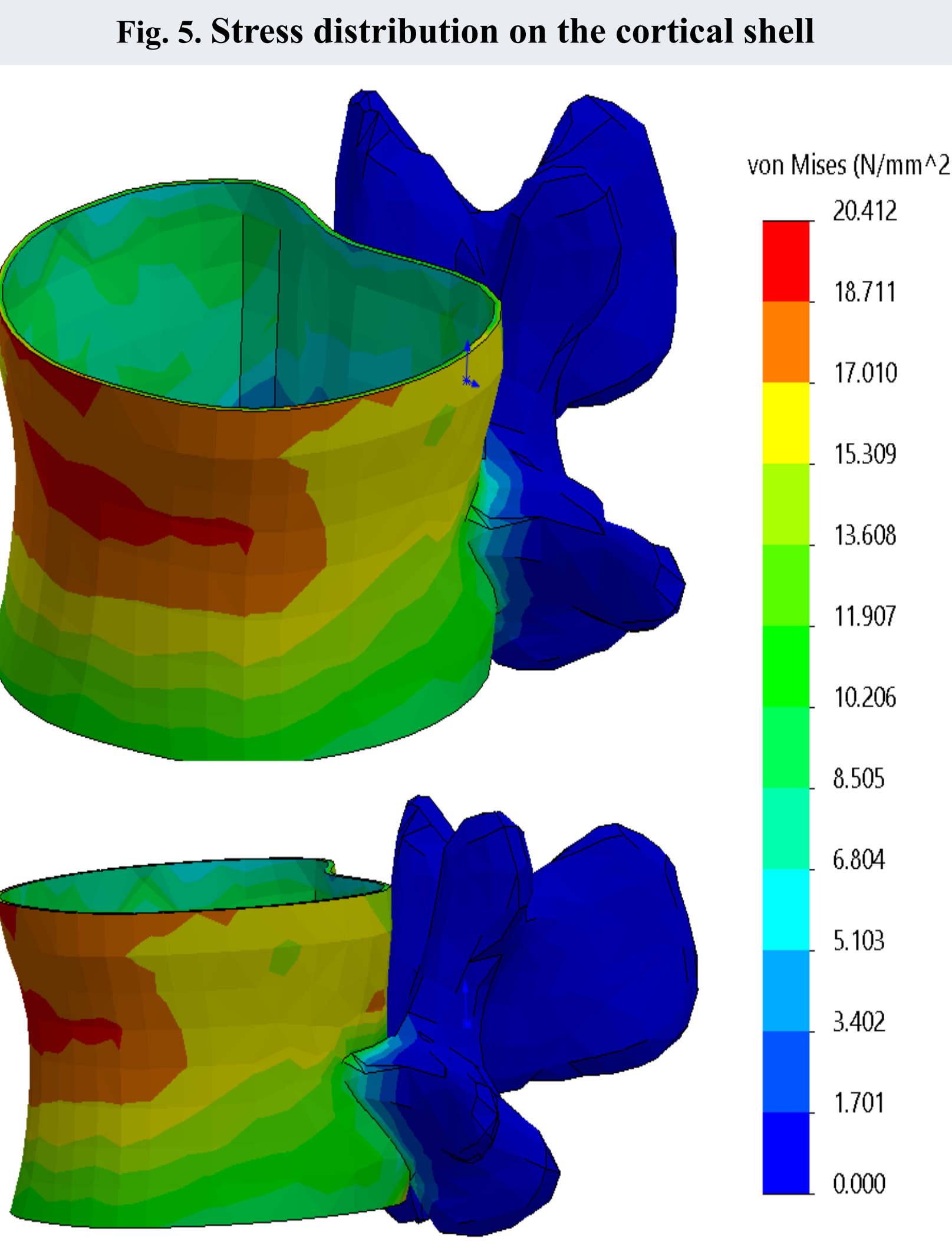

NUMERICAL RESULTS

Fig. 6. Von Mises stress for $0.5 \mathrm{~mm}$ cortical shell thickness

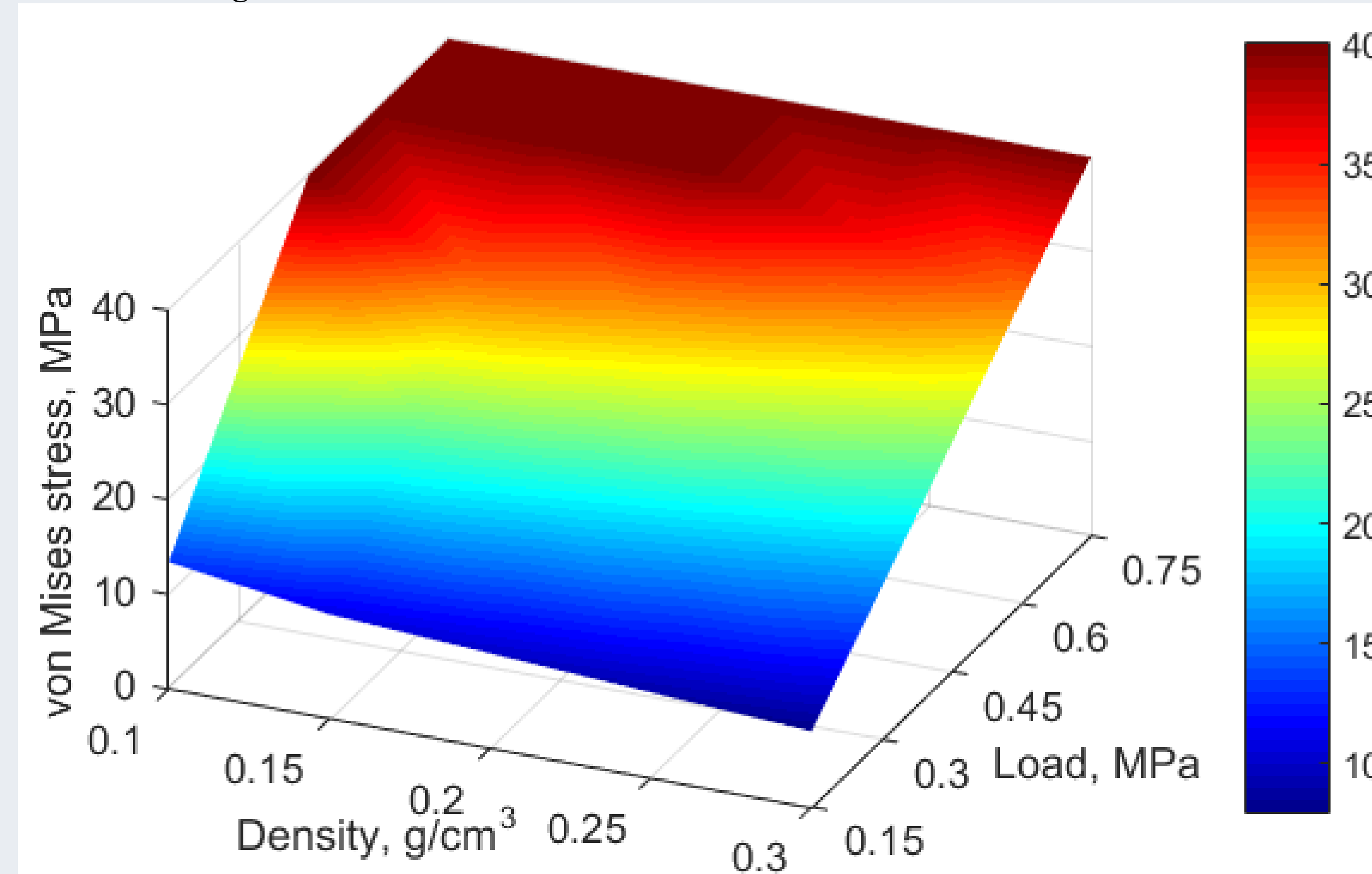

Fig. 7. Von Mises stress for $0.4 \mathrm{~mm}$ cortical shell thickness
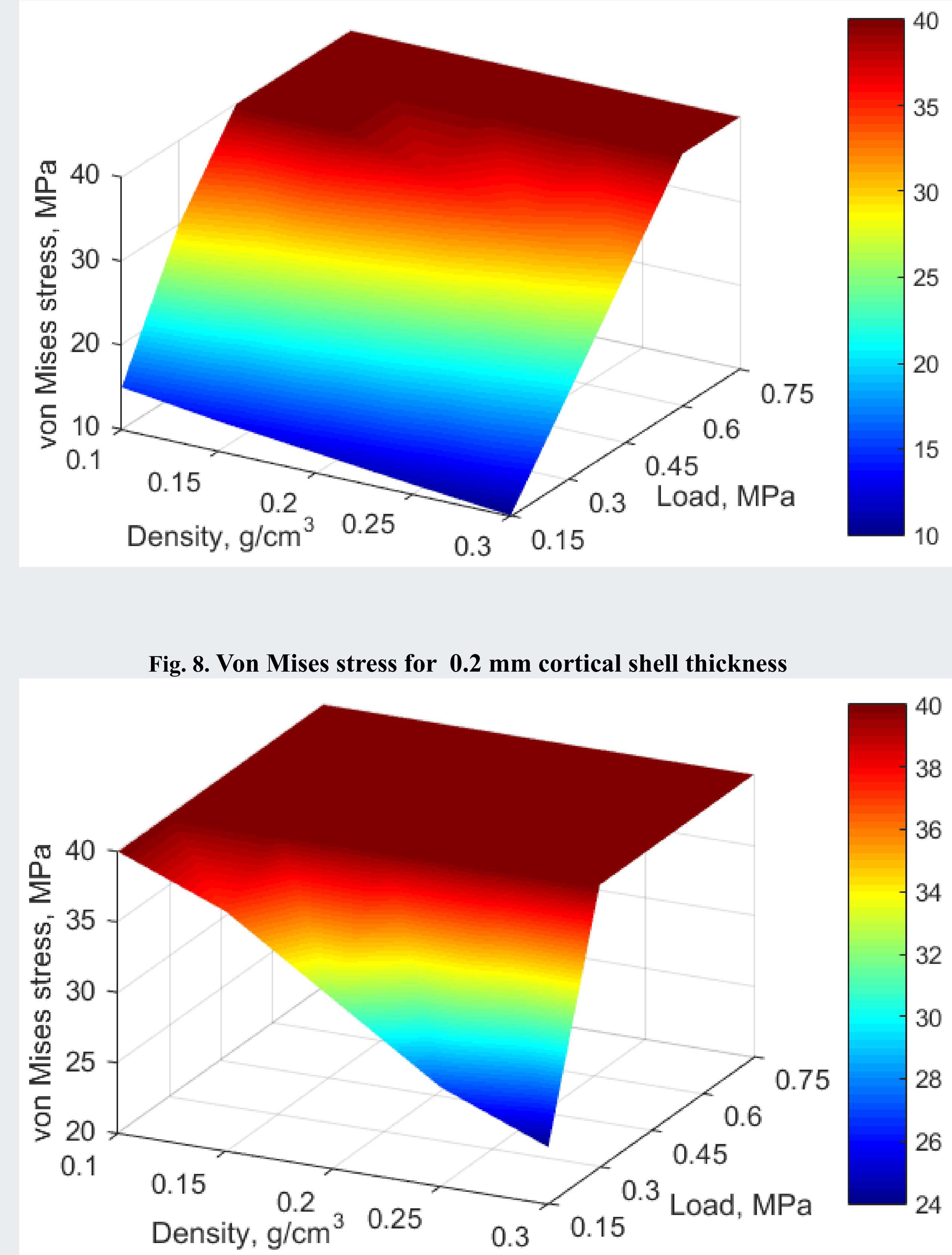

CONCLUSION

We developed the L1 vertebra model, which consisted of cortical shell, cancellous bone and intervertebral disks. The model was treated for three grades of degenerative diseases. The model was stress, which was assumed to predict the risk of fracture, was determined for three different thicknesses of cortical shell and different apparent density of cancellous bone (in range of $0.1-0.3 \mathrm{~g} / \mathrm{cm}^{3}$ ). The results showed that the von-Mises stress was substantially higher under relatively low levels of apparent density, and critical due do thenerative bone dise which suggests that palients with In addition, this model could

tesld be easily individualized according to the anatomical peculiar properties of patients.

REFERENCES

1. Lin, J. T., Lane, J. M. Osteporossis: a r
Related Research, 2004, vol. $425,34-42$. Nevitt, M. C., e.t. al. Association of prevalent vertebral fractures, bone
density and alendronate treatment with incididnt verterbal fractures: Johnell, O., et. al. Mortality after osteoporotic fractures. Osteoporosis
International, 2004, vol. 15 , p. $38-42$. Dreischarf, M. et al. Comparison of eight published static finite element

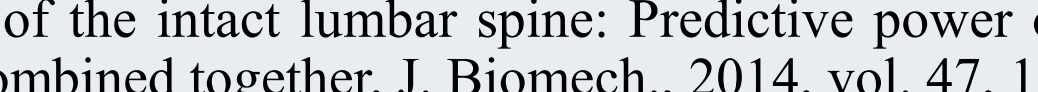
Wolfram, U., et al. Yield criteria for vertebral trabecular bone in stress
and strain space, J. Mech. Behav. Biomed. Mater, 2012, vol. 15, 218-228. Helgason, B. et al. Mathematical relationships between bone density and
mechanical propertites: A literature review, Clin. Biomech. 2008, vol. 23,

Contact address: Oleg Ardatov

Email: oleg.ardatov@vgtu.lt Faculty of Mechanics, 